\title{
Optimization of Process Parameters of Surfactant and Graphite Powder Mixed Dielectric EDM through Taguchi-Grey Relational Analysis
}

\author{
V. Vikram Reddy, Ch. Sridhar Reddy and P. Madar Valli
}

\begin{abstract}
This paper presents an optimization of process parameters of Electrical Discharge Machining (EDM) process with surfactant and graphite powder mixed dielectric using multi- response optimization Grey Relational Analysis (GRA) method instead of single response optimization. These parameters were optimized based on Taguchi orthogonal array (OA) combined with Grey Relational Analysis. A grey relational grade (GRG) was calculated based on Grey Relational Analysis. A grey relational grade is used to optimize the EDM process with multiple performance characteristics. Taguchi L9 orthogonal array was used to design the experiments. The machining parameters such as peak current, surfactant concentration, and graphite powder concentration were chosen for experimentation. The performance characteristics chosen for this study are material removal rate (MRR), tool wear rate (TWR) and surface roughness (SR). Experiments were conducted using electrolyte copper as the tool and PH17-4 stainless steel as the work piece. Results revealed that machining performance has been improved considerably using this approach. The confirmation experiments were conducted at optimum parametric setting and it was found that the predicted values of responses at optimal combination of parameters are in good agreement with the results of confirmation experiments.
\end{abstract}

Keywords--- Electrical Discharge Machining, Surfactant Concentration, Graphite Powder Concentration, Material Removal Rate, Tool Wear Rate, Surface Roughness, MultiResponse Optimization, Taguchi Method, Grey Relational Analysis

\section{INTRODUCTION}

$\mathrm{E}$ LECTRICAL discharge machining (EDM) is one of the most widely used advanced machining processes in manufacturing industries to make die of complex cavities, automotive, aerospace and surgical components and machining of electrically conductive materials irrespective of the hardness.

V. Vikram Reddy, Professor, Mechanical Engineering, Jayamukhi Institute of Technological Sciences, Warangal-506331, T.S, India. E-mail:vaddi.vikramreddy@gmail.com

Ch. Sridhar Reddy, Associate Professor, Mechanical Engineering, JNTUCE, Manthini, T.S, India.E-mail:reddy.chsridhar@gmail.com

P. Madar Valli, Professor, Mechanical Engineering, A.I.T.S, Rajampet, A.P, India. E-mail:dr.pmvalli@ gmail.com

DOI: $10.9756 /$ BIJIEMS.10433
In EDM removal of material from work surface by means of successive electrical discharges occurring between an electrode and a workpiece when both are immersed in a dielectric and are separated by small gap. The required properties of dielectric fluid are low viscosity, high dielectric strength, and rapid recovery after break down, efficient cooling and flushing ability. Spark is initiated at the peak between the contacting surfaces of electrode and workpiece and occurs momentarily. The material is removed from the work piece by localized melting and even vaporization of material by high temperature spark. Optimization of EDM is required to reduce its production cost and improve product quality. Thus the main advantage of this is that there is no physical contact between the tool and work piece which eliminates mechanical stresses, chatter and vibration problems during machining that enables EDM to machine even brittle materials. The wide applications and usage of this process made many manufacturing research engineers to bestow more attention into the rudiments of this process to enhance the process capabilities and applications. For example the rotary motion of work piece improves the dielectric circulation through the discharge gap resulting in increase in material removal rate (MRR) [5]. Machining characteristics of EN8 steel with disc type rotating copper electrode during rotary EDM have been studied [3]. The effect of axial vibration of tool along with rotation on MRR and tool wear rate (TWR) during EDM was studied [4]. The significant increase in the performance of PMEDM over conventional EDM was noticed with the addition of silicon powder into dielectric fluid [6]. The improvement in performance of EDM was also noticed with mixing of silicon powder in dielectric [11]. The optimization of process parameters such as current, pulse on time, concentration of Silicon powder, duty cycle of powder mixed electrical discharge machining (PMEDM) has been done with considering responses as MRR and surface roughness (SR) using Response Surface Methodology (RSM) [7]. The machining characteristics of $\gamma$-TiAl were explored during PMEDM using addition of different powders namely aluminium, chrome, silicon carbide, graphite and iron into the dielectric fluid. The chosen responses such as SR, topography, MRR, electro chemical corrosion resistance were studied [2]. The improvement of surface properties (improved surface roughness, increased Vickers microhardness) with $\mathrm{Si}, \mathrm{W}$ and graphite powders mixed in dielectric in powder mixed EDM process were noticed [1]. The wide applications and usage of this process made many manufacturing research engineers to bestow more attention into the rudiments of this process to enhance the process capabilities and optimization of 
performance characteristics of EDM process. The different optimization methods used were Taguchi method, response surface methodology, artificial neural network, genetic algorithm, grey relational analysis, fuzzy logic etc, by varying different electrical and non-electrical process parameters.

A new approach was applied for optimization of PMEDM process with multiple performance characteristics based on orthogonal array with grey relational analysis [9]. Experiments were performed on stir casted 6061 Al/Al2O3p/20p and investigated effects of process parameters on performance of PMEDM with silicon carbide powder mixed dielectric fluid and interaction of mechanical abrasion and thermal process [14]. An attempt was made to develop a model for optimizing PMEDM characteristics using a mixed orthogonal array $\mathrm{L}_{18}$ experimental design [15]. An attempt was made to predict surface finish during electrical discharge machining using neural network models [10]. Optimal combination of processes parameters of powder mixed electrical discharge machining (PMEDM) using response surface methodology (RSM) to plan and analyze the experiments. Pulse on time, duty cycle, peak current, and concentration of the silicon powder added into the dielectric were chosen as process parameters to study the process performance in terms of MRR and SR. The work material chosen for study are EN31 and AISI 52100 tool steel [8]. Taguchi approach was used to find effect of surfactant and $\mathrm{Al}$ powder mixed dielectric (kerosene) during EDM of SKD 61 tool steel on the performance measure surface finish of workpiece after EDM [18]. Response surface methodology was applied during EDM of Ti6246 workpiece with silicon carbide (SiC) powder mixed dielectric. Further, mathematical relations were developed to correlate process parameters with responses [13]. Hybrid model was developed to optimize surface roughness in EDM using ANN and genetic algorithm. Multi perceptron neural network models were developed using the neurosolutions package. The genetic algorithm concept was used to optimize the weighting factors of the network [12]. Investigated the effect of surfactant and graphite powder mixed dielectric on EDM performance characteristics such as MRR, SR, white layer thickness and surface crack density [16]. The significance of surfactant and graphite powder mixed dielectric on MRR, TWR and SR have reported and also process parameters were optimized using Taguchi-DEAR multi response optimization method [17].

From the literature, it has been observed that no extensive work has been carried out so far EDM of precipitation hardening stainless steel PH17-4 using surfactant and graphite powder mixed EDM oil (SAE4050) as dielectric and electrolyte copper as electrode. The present work aims to optimize processes parameters of EDM to obtain maximum MRR, minimum TWR and SR simultaneously using multi response optimization grey relational analysis method.

\section{EXPERIMENTAL SETUP, PROCEDURE AND EQUIPMENT}

For conducting experiments, the work material PH17-4 stainless steel rolled bar is cut into the sample pieces with the dimensions of $80 \times 30 \times 6 \mathrm{~mm}^{3}$. The mechanical and physical properties of PH 17-4 steel are presented in Table1. The electrolyte copper of diameter $\varnothing 14 \mathrm{~mm}$ and length $70 \mathrm{~mm}$ was used as tool material for machining PH17-4 stainless steel and its physical properties are presented in the Table2.

Table 1: Physical and Mechanical Properties of PH17-4 Stainless Steel

\begin{tabular}{|l|l|}
\hline Density & $7.8\left(\mathrm{~g} / \mathrm{cm}^{3}\right)$ \\
\hline Specific capacity & $400\left(\mathrm{~J} / \mathrm{kg}^{\circ} \mathrm{k}\right)$ \\
\hline Thermal conductivity & $18.4\left(\mathrm{~W} / \mathrm{m}^{\circ} \mathrm{k}\right)$ \\
\hline Electrical resistivity & $0.08 \times 10^{-} 6 \Omega \mathrm{m}$ \\
\hline Modulus of elasticity & $196 \mathrm{G} \mathrm{Pa}$ \\
\hline
\end{tabular}

Table 2: Physical properties of electrolyte copper

\begin{tabular}{|l|l|}
\hline Density & $8.95\left(\mathrm{~g} / \mathrm{cm}^{3}\right)$ \\
\hline Specific capacity & $383\left(\mathrm{~J} / \mathrm{kg}^{\circ} \mathrm{C}\right)$ \\
\hline Thermal conductivity & $394\left(\mathrm{~W} / \mathrm{m}^{\circ} \mathrm{C}\right)$ \\
\hline Electrical resistivity & $1.673 \times 10^{-} 8 \Omega \mathrm{m}$ \\
\hline Melting point & $1083^{\circ} \mathrm{C}$ \\
\hline
\end{tabular}

Table 3: Input Process Parameters and their Levels

\begin{tabular}{|l|l|l|l|l|}
\hline Parameter & Units & Level1 & Level2 & Level3 \\
\hline Peak current, I & Amps & 10 & 15 & 20 \\
\hline Surfactant concentration, SC & g/lt & 4 & 6 & 8 \\
\hline Graphite Powder concentration, PC & g/lt & 4.5 & 9 & 13.5 \\
\hline
\end{tabular}

Table 4: Experimental Conditions

\begin{tabular}{|l|l|}
\hline Working conditions & Description \\
\hline Work piece & PH17-4 stainless steel $(80 \mathrm{~mm} \times 30 \mathrm{~mm} \times 6 \mathrm{~mm})$ \\
\hline Electrode & Electrolyte copper $\varnothing 14 \mathrm{~mm}$ and length $70 \mathrm{~mm}$ \\
\hline Flushing & Side flushing with pressure 0.5MPa \\
\hline Dielectric & Commercial EDM Oil grade SAE 450+Gr.powder+surfactant SPAN20 \\
\hline Gr. Powder particle size & $20-30 \mu \mathrm{m}$ \\
\hline Polarity & Normal \\
\hline Supply voltage & $110 \mathrm{~V}$ \\
\hline Gap voltage & $70 \mathrm{~V}$ \\
\hline Pulse on time & $45 \mu \mathrm{s}$ \\
\hline Pulse off time & $48 \mu \mathrm{s}$ \\
\hline Machining time & 3 minutes \\
\hline
\end{tabular}


Table 5: Experimental layout using an $\mathrm{L}_{9}\left(3^{4}\right) \mathrm{OA}$

\begin{tabular}{|l|l|l|l|}
\hline Exp.No. & Discharge Current & Surfactant concentration & Gr. Powder concentration \\
\hline 1 & 1 & 1 & 1 \\
\hline 2 & 1 & 2 & 2 \\
\hline 3 & 1 & 3 & 3 \\
\hline 4 & 2 & 1 & 2 \\
\hline 5 & 2 & 2 & 3 \\
\hline 6 & 2 & 3 & 1 \\
\hline 7 & 3 & 1 & 3 \\
\hline 8 & 3 & 2 & 1 \\
\hline 9 & 3 & 3 & 2 \\
\hline
\end{tabular}

The dielectric fluid EDM oil grade SAE450 was used to conduct all experiments. All the experiments were conducted on die sinking EDM machine of FORMATICS 50 model which is equipped with ELECTRONICA PRS 20 controller. Modified working fluid circulating system has been designed for experimentation. In modified system, a separate tank mounted with micro pump is installed for better circulation of graphite powder and surfactant-mixed dielectric fluid. A motorized stirring system is incorporated to avoid settling of powder particles. The chosen process parameters and corresponding levels for this study are presented in the Table3. The chosen experimental conditions are presented in the Table4. The design of experiment (DOE) chosen for this study was a Taguchi L9 Orthogonal array and is presented in Table4. Machining time has been chosen for conducting each experiment is 3 minutes. A digital weighing balance (citizen) having capacity up to 300 grams with a resolution of $0.1 \mathrm{mg}$ was used for weighing the work pieces and electrodes before machining and after machining. Then the material removal rate (MRR) and tool wear rate (TWR) are calculated using equations (1-2).

$$
\begin{aligned}
& \operatorname{MRR}\left(\mathrm{mm}^{3} / \min \right)=\frac{\Delta W}{\rho_{w} \times t} \ldots . . \\
& \operatorname{TWR}\left(\mathrm{mm}^{3} / \min \right)=\frac{\Delta T}{\rho_{t} \times t} \ldots \ldots .
\end{aligned}
$$

where $\Delta W$ is the weight difference of work piece before and after machining $(\mathrm{g}), \rho_{w}$ is density of work material $\left(\mathrm{g} / \mathrm{mm}^{3}\right), \Delta T$ is the weight difference of electrode before and after machining $(\mathrm{g}), \rho_{t}$ is density of electrode material $\left(\mathrm{g} / \mathrm{mm}^{3}\right)$ and $t$ is machining time in minutes. Surface roughness of the machined work pieces were measured using Talysurf surface roughness tester. The surface roughness is represented by the centre line average method (Ra). Roughness measurements were carried out in the transverse direction on machined surface with sampling length of $0.8 \mathrm{~mm}$ and were repeated three times and average values are calculated.

The Taguchi method uses S/N (Signal to Noise) ratio to measure the deviation of performance characteristics from the desired values. These are three categories of $\mathrm{S} / \mathrm{N}$ ratios depending on the types of characteristics like higher the better (HB), lower the better (LB) and nominal the better (NB). In EDM process, the main objective is to increase MRR and to reduce SR and TWR. Hence higher the better has been employed for MRR whereas the lower the better has been applied for SR and TWR.

For higher the better,

$$
S / N \text { ratio }=-10 \log \left(\frac{1}{n}\right) \sum \frac{1}{Y_{i j}^{2}}
$$

For lower the better,

$$
S /{ }_{N} \text { ratio }=-10 \log \left(\frac{1}{n}\right) \sum Y_{i j}^{2}
$$

Where $\mathrm{n}$ is the number of replications for each experiment and $Y_{i j}$ is the response values. Table6 shows obtained average values of each response from each experiment and their corresponding $\mathrm{S} / \mathrm{N}$ ratios.

Table 6: Average Values of MRR, SR and TWR and Corresponding S/N ratios

\begin{tabular}{|c|c|c|c|c|c|c|c|c|c|}
\hline \multirow{2}{*}{ Exp.No. } & \multicolumn{3}{|c|}{ Processes parameters } & \multicolumn{4}{|c|}{ Responses (mean) } & \multicolumn{3}{c|}{ S/N ratios of responses } \\
\cline { 2 - 10 } & $\begin{array}{c}\text { I } \\
(\mathrm{A})\end{array}$ & $\begin{array}{c}\mathrm{SC} \\
(\mathrm{g} / \mathrm{lt})\end{array}$ & $\begin{array}{c}\text { PC } \\
(\mathrm{g} / \mathrm{lt})\end{array}$ & $\begin{array}{c}\text { MRR } \\
\left(\mathrm{mm}^{3} / \mathrm{min}\right)\end{array}$ & $\begin{array}{c}\text { TWR } \\
\left(\mathrm{mm}^{3} / \mathrm{min}\right)\end{array}$ & $\begin{array}{c}\text { SR } \\
(\mu \mathrm{m})\end{array}$ & $\begin{array}{c}\text { MRR } \\
(\mathrm{dB})\end{array}$ & $\begin{array}{c}\text { TWR } \\
(\mathrm{dB})\end{array}$ & $\begin{array}{c}\text { SR } \\
(\mathrm{dB})\end{array}$ \\
\hline 1 & 10 & 4 & 4.5 & 29.04 & 0.59 & 3.1 & 29.2599 & 4.5830 & -9.8272 \\
\hline 2 & 10 & 6 & 9 & 37.48 & 0.54 & 3.7 & 31.4760 & 5.3521 & -11.3640 \\
\hline 3 & 10 & 8 & 13.5 & 31.11 & 1.19 & 3.6 & 29.8580 & -1.5109 & -11.1261 \\
\hline 4 & 15 & 4 & 9 & 42.97 & 3.57 & 6.8 & 32.6633 & -11.0534 & -16.6502 \\
\hline 5 & 15 & 6 & 13.5 & 53.17 & 3.73 & 7.9 & 34.5133 & -11.4342 & -17.6163 \\
\hline 6 & 15 & 8 & 4.5 & 43.60 & 5.40 & 6.4 & 32.7897 & -14.6479 & -16.1236 \\
\hline 7 & 20 & 4 & 13.5 & 52.09 & 3.81 & 6.64 & 34.3351 & -11.6185 & -16.4434 \\
\hline 8 & 20 & 6 & 4.5 & 60.76 & 6.02 & 7.8 & 35.6724 & -15.5919 & -17.8419 \\
\hline 9 & 20 & 8 & 9 & 54.01 & 5.52 & 7.5 & 34.6495 & -14.8388 & -17.5012 \\
\hline
\end{tabular}

In the present study, grey relational approach is used to get optimal combination of process parameters. In this method multiple performance characteristics can be converted into single grey relational grade and the step by step procedure is as follows.
Step1: Pre-processing of the data was first performed for normalizing the raw data $(\mathrm{S} / \mathrm{N}$ ratios obtained from the Taguchi analysis) for analysis. Yij is normalized as $\mathrm{Xij}(0 \leq \mathrm{Xij}$ $\leq 1)$ as follows to avoid the effect of adopting different units and to reduce the variability. 
For higher the better characteristic,

$$
X_{i j}=\frac{\left(Y_{i j}-\min \left(Y_{i j}\right)\right)}{\left(\max \left(Y_{i j}\right)-\min \left(Y_{i j}\right)\right)}
$$

For lower the better characteristic,

$$
X_{i j}=\frac{\left(\max \left(Y_{i j}\right)-Y_{i j}\right)}{\left(\max \left(Y_{i j}\right)-\min \left(Y_{i j}\right)\right)}
$$

Where $\mathrm{Xij}$ is normalized $\mathrm{S} / \mathrm{N}$ ratio, Yij is the $\mathrm{S} / \mathrm{N}$ ratio obtained from the Taguchi analysis and min (Yij) and max (Yij) are minimum and maximum values of $\mathrm{S} / \mathrm{N}$ ratio respectively.

Step2: The grey relational coefficient can be calculated as

$$
G C_{i j}=\frac{\left(\Delta_{\min }+\Psi \Delta_{\max }\right)}{\left(\Delta_{i j}+\Psi \Delta_{\max }\right)}
$$

where $G C_{i j}$ is the grey relational coefficient.

Since multi response characteristics consist of both higher the better and lower the better hence $\Psi$ is assumed as 0.5 . $\Delta_{\min }$ and $\Delta_{\max }$ are the minimum and maximum absolute difference that is a deviation from target value. This can be treated as quality loss.
Step3: After averaging the grey relational coefficients, grey relational grade $(\mathrm{Gi})$ can be calculated as

$$
G_{i}=\frac{1}{m} \sum G C_{i j}
$$

Where $\mathrm{m}$ is the number of response variables. Higher value of grey relational grade specifies the stronger relational degree between ideal sequence and present sequence. Ideal sequence is the best response in the machining process. Higher grey grade indicates closer to the optimal response in the process.

\section{RESULTS AND DiSCUSSION}

Table6 presents $\mathrm{S} / \mathrm{N}$ ratio values for MRR, SR and TWR. Table7 presents normalized $\mathrm{S} / \mathrm{N}$ ratio values and deviation of sequences for MRR, SR and TWR. These values have been converted into grey relational coefficients as per steps involved in grey relational analysis. As mentioned above, distinguishing coefficient has been taken as 0.5. After calculating grey relational coefficients, grey relational grade (GRG) has been evaluated as said earlier. The rank of each trial is mentioned based on grey relational grade and is shown in Table8. The higher grey relational grade will have better multi-response characteristics.

Table 7: Normalized S/N Ratios and Deviation Sequences for MRR, TWR and SR

\begin{tabular}{|l|l|l|l|l|l|l|l|l|l|}
\hline \multirow{2}{*}{ Exp.No. } & \multicolumn{3}{|l}{ Process parameters } & \multicolumn{2}{l}{ Normalized S/N ratios } & \multicolumn{2}{l|}{ Deviation sequences } \\
\cline { 2 - 11 } & $\mathrm{I}(\mathrm{A})$ & $\mathrm{SC}(\mathrm{g} / \mathrm{lt})$ & $\mathrm{PC}(\mathrm{g} / \mathrm{lt})$ & MRR & TWR & SR & MRR & TWR & SR \\
\hline 1 & 10 & 4 & 4.5 & 0 & 0.3672 & 0 & 1 & 0.6328 & 1 \\
\hline 2 & 10 & 6 & 9 & 0.3456 & 0 & 0.1917 & 0.6544 & 1 & 0.8083 \\
\hline 3 & 10 & 8 & 13.5 & 0.0932 & 0.3276 & 0.1620 & 0.9068 & 0.6724 & 0.838 \\
\hline 4 & 15 & 4 & 9 & 0.5307 & 0.7853 & 0.8513 & 0.4693 & 0.2167 & 0.1487 \\
\hline 5 & 15 & 6 & 13.5 & 0.8192 & 0.8014 & 0.9718 & 0.1808 & 0.1986 & 0.0282 \\
\hline 6 & 15 & 8 & 4.5 & 0.5504 & 0.9549 & 0.7850 & 0.4496 & 0.0451 & 0.2144 \\
\hline 7 & 20 & 4 & 13.5 & 0.7914 & 0.8102 & 0.8255 & 0.2086 & 0.1898 & 0.1745 \\
\hline 8 & 20 & 6 & 4.5 & 1 & 1 & 1 & 0 & 0 & 0 \\
\hline 9 & 20 & 8 & 9 & 0.8404 & 0.9640 & 0.9574 & 0.1596 & 0.036 & 0.0426 \\
\hline
\end{tabular}

Table 8: Grey Relational Coefficients and Grey Relational Grade

\begin{tabular}{|l|l|l|l|l|l|l|l|l|}
\hline \multirow{2}{*}{ Exp. No. } & \multicolumn{3}{|l|}{ Process parameters } & \multicolumn{2}{l|}{ Grey relational coefficients } & $\begin{array}{l}\text { Grey relational } \\
\text { grade }\end{array}$ & \multirow{2}{*}{ Rank } \\
\cline { 2 - 8 } & $\mathrm{I}(\mathrm{A})$ & $\mathrm{SC}(\mathrm{g} / \mathrm{lt})$ & $\mathrm{PC}(\mathrm{g} / \mathrm{lt})$ & MRR & TWR & SR & \\
\hline 1 & 10 & 4 & 4.5 & 0.3333 & 0.4413 & 0.3333 & 0.3693 & 9 \\
\hline 2 & 10 & 6 & 9 & 0.4331 & 0.3333 & 0.3821 & 0.3828 & 8 \\
\hline 3 & 10 & 8 & 13.5 & 0.3554 & 0.4264 & 0.3736 & 0.3851 & 7 \\
\hline 4 & 15 & 4 & 9 & 0.5158 & 0.6976 & 0.7707 & 0.6613 & 6 \\
\hline 5 & 15 & 6 & 13.5 & 0.7344 & 0.7157 & 0.9466 & 0.7989 & 3 \\
\hline 6 & 15 & 8 & 4.5 & 0.5265 & 0.9172 & 0.6998 & 0.7145 & 5 \\
\hline 7 & 20 & 4 & 13.5 & 0.7056 & 0.7248 & 0.7412 & 0.7238 & 4 \\
\hline 8 & 20 & 6 & 4.5 & 1 & 1 & 1 & 1 & 1 \\
\hline 9 & 20 & 8 & 9 & 0.9214 & 0.9328 & 0.9214 & 0.8707 & 2 \\
\hline
\end{tabular}

The average grey relational grade value for each level of the chosen process parameters is presented in Table9. These values were calculated through averaging values of each level group during all the levels of process parameters. Since GRG indicates the level of relationship between reference sequence and obtained sequence, hence higher value of average GRG denotes stronger relationship between them that means it designates optimal level of process parameters. The higher $\Delta$ value indicates the significant nature on determining response in the process. 
Table 9: Average Grey Relational Grade of Each Level of Corresponding Factor

\begin{tabular}{|l|l|l|l|c|l|}
\hline Parameter & Level 1 & Level 2 & Level 3 & $\Delta$ & Rank \\
\hline $\mathrm{I}(\mathrm{A})$ & 0.3790 & 0.7249 & $0.8648^{*}$ & 0.4858 & 1 \\
\hline $\mathrm{SC}(g / l t)$ & 0.5848 & $0.7762^{*}$ & 0.6649 & 0.1914 & 2 \\
\hline $\mathrm{PC}(g / l t)$ & $0.7861^{*}$ & 0.6545 & 0.6223 & 0.1638 & 3 \\
\hline
\end{tabular}

It was observed that peak current is most significant factor, and then follows surfactant concentration and powder concentration having significant affect on the EDM process. From Table9 it was observed the optimal combination of

$$
\text { predicted response }=\text { Average of } I_{3}+\text { Average of } S C_{2}+\text { Average of } P C_{1}-2 \times \text { Mean of response }\left(Y_{i j}\right)
$$

Further, confirmation experiment was performed at optimum process parametric setting (I3-SC2-PC1) to validate the predicted values. The experimental, predicted values of

each response and calculated percentage error and were presented in Table10.

Table10: Experimental, Predicted Values of Responses at Optimum Parametric Setting

\begin{tabular}{|l|l|l|}
\hline \multirow{2}{*}{ Response } & \multicolumn{2}{|l|}{ Optimal process parameters } \\
\cline { 2 - 3 } & Predicted value & Experimental value \\
\hline Level & $\mathrm{A}_{3} \mathrm{~B}_{2} \mathrm{C}_{1}$ & $\mathrm{~A}_{3} \mathrm{~B}_{2} \mathrm{C}_{1}$ \\
\hline $\mathrm{MRR}\left(\mathrm{mm}^{3} / \mathrm{min}\right)$ & 60.72 & 60.76 \\
\hline $\mathrm{TWR}\left(\mathrm{mm}^{3} / \mathrm{min}\right)$ & 5.79 & 6.02 \\
\hline $\mathrm{SR}(\mu \mathrm{m})$ & 7.62 & 7.8 \\
\hline
\end{tabular}

From the Table10 it was observed that predicted values are in good agreement with experimental values.

\section{CONCLUSION}

In this work, Taguchi L9 array with grey relational analysis was used to optimize the multiple performance characteristics such as material removal rate, tool wear rate and surface roughness. It is found that the significance of each process parameter in sequence is peak current is most significant factor then surfactant concentration and graphite powder concentration based on largest $\Delta$ value which was found from response table9. The optimal combination of process parameters were obtained using GRA. Confirmation experiments were conducted at optimal parametric setting. Further, at optimum parametric setting, predicted values are in good agreement with experimental results.

\section{REFERENCE}

[1] Anirban Bhattacharya., Ajay Batish. and Naveen Kumar., "Surface characterization and material migration during surface modification of die steels with silicon, graphite and tungsten powder in EDM process," Journal of Mechanical Science and Technology, Vol. 27, No. 1, Pp.133140, 2013.

[2] Behzad Jabbaripour., Mohammad Hossein Sadeghi., "Mohammed Reza Shabgard. and Hossein Faraji., Investigating surface roughness, material removal rate and corrosion resistance in PMEDM of $\gamma$-TiAl intermetallic," Journal of Manufacturing Processes, Vol. 15, No. 1, Pp. 56-68, 2013.

[3] Chattopadhyay, K. D., Verma, S., Satsangi, P.S. and Sharma, P.C., "Development of empirical model for different process parameters during rotary electrical discharge machining of copper-steel (EN-8) system, "J Mater Process Technol, Vo1.209, Pp. 1454-1465, 2009.

[4] Ghoreishi, M. and Atkinson, J., "A comparative experimental study of machining characteristics in vibratory, rotary and vibro-rotary electrodischarge machining”. J. Mater. Process. Tech., Vol.120, Pp. 374-378, 2002. process parameters is when I at 20A (level 3), SC at $6 \mathrm{~g} / \mathrm{lt}$ (level2), and PC at 4.5g/lt (level1). Further each response value is predicted as follows based on grey relational analysis.

[5] Guu, Y.H. and Hocheng, H., "Effects of workpiece rotation on machinability during electrical discharge machining," J. Mater. Manuf. Processes, Vol. 16, No. 1, Pp. 91-101, 2001.

[6] Kansal, H.K., Singh, S. and Kumar, P., "An experimental study of the machining parameters in powder mixed electric discharge machining of $\mathrm{Al}-10 \% \mathrm{SiCP}$ metal matrix composites," International Journal of Manufacturing Technology and Management, Vol. 1, No. 4, Pp. 396$411,2006$.

[7] Kansal, H.K., Singh, S. and Kumar, P., "Parametric optimization of powder mixed electrical discharge machining by response surface methodology," Journal of Materials Processing Technology, Vol. 169, pp. 427-436, 2005.

[8] Lin, J.L. and Lin, C.L., "The use of the orthogonal array with grey relational analysis to optimize the electrical discharge machining process with multiple performance characteristics," International Journal of Machine Tools and Manufacture, Vol. 42, Pp.237-244, 2002.

[9] Panda, D.K. and Bhoi, R.K., "Artificial neural network prediction of material removal rate in electro discharge machining," Materials and Manufacturing Processes, Vol. 209, No. 4, Pp. 645-672, 2005.

[10] Pecas, P. and Henriques, E., "Influence of silicon powder-mixed dielectric on conventional electrical discharge machining," International Journal of Machine Tools and Manufacture, Vol. 43, No. 14, pp. 1465$1471,2003$.

[11] Rao, K.M., Rangajanardhaa, G., Hanumantha Rao, G.D. and Sreenivasa Rao, M. "Development of hybrid model and optimization of surface roughness in electric discharge machining using artificial neural networks and genetic algorithm," Journal of Materials Processing Technology, Vol. 209, No. 3, pp. 1512-1520, 2009.

[12] Sharif, S. and Noordin, R.M.Y., Mach inability modeling in powder mixed dielectric EDM of titanium alloy Ti_6246. Proceedings of the First International Conference and Seventh AUN/SEED8Net Field wise Seminar on Manufacturing and Material Processing, 14-15 March, Kuala Lumpur, Malasia,; Pp. 133-138, 2006.

[13] Singh, S., Maheshwari, S. and Dey, A., "Electrical Discharge Machining (EDM) of aluminum metal matrix composites using powder suspended dielectric fluid," Journal of Mechanical engineering, Vol. 57, No. 5, Pp. 271-290, 2006.

[14] Tsai, K.M. and Wang, P.J., "Predictions on surface finish in electrical discharge machining based upon neural network models," International journal of Machine Tools \& Manufacture, Vol. 41, No. 10, pp. 13851403, 2001.

[15] V.Vikram Reddy, A.Kumar, P.Madar Valli and Ch.Sridhar Reddy, "Influence of surfactant and graphite powder concentration on electrical discharge machining of PH17-4 stainless steel," Journal of the Brazilian 
Society of Mechanical Sciences and Engineering,DOI 10.1007/s40430014-0193-4,Vol.37, No.2, pp 641-655, 2015.

[16] V.Vikram Reddy, P.Madar Valli, A.Kumar and Ch.Sridhar Reddy, "Multi-objective optimization of electrical discharge machining of PH17-4 stainless steel with surfactant-mixed and graphite powdermixed dielectric using Taguchi-data envelopment analysis-based ranking method," Proceedings of the Institution of Mechanical Engineers, Part B: Journal of Engineering Manufacture, DOI: 10.1177/0954405414530904, Vol. 229, No. 3, Pp 487-494, 2015.

[17] Wu, K.L., Yan, B.H., Huang, F.Y. and Chen, S.C., "Improvement of surface finish on SKD steel using electro discharge machining with aluminum and surfactant added dielectric," International Journal of Machine Tools and Manufacture, Vol. 45, Pp. 1195-1201, 2005. 